\title{
A Pilot Study of a Cross-Sector Partnership to Integrate Inner-City Community College Students into a School Based Health Promotion Program
}

\author{
Stacia Reader and Charmaine Aleong \\ Department of Health Physical Education and Recreation, Bronx Community College
}

\begin{abstract}
While overweight and obesity continue to be significant public health problems in the United States, especially among minority and disadvantaged youth, there are also many initiatives in the school environment that aim to combat these concerns. The effectiveness of these interventions is of course a major point of interest. This paper describes issues raised in an early-stage cross-sector partnership between a community-based organization (CBO) and an urban community college for tackling obesity in public school children. Seven college students worked as paid interns in the CBO's New York City Public School-based health promotion program located in the Bronx. As part of the program, college students paired with chefs to educate schoolchildren about healthy eating. This study examines the successes, challenges and lessons learned from the themes that arose in the college students' pre and post surveys and logs, faculty journal entries and notes from a debriefing session with CBO staff. The college students reported multiple successes such as applying their nutrition knowledge, an interest in working in their community and positive changes in some of the schoolchildren's and college students' eating behaviors. Challenges included a short and chaotic lunch period, which discouraged healthy eating, and a lack of buy-in from the school staff and parents. This study highlights the issue of cultural relatability and the effectiveness of role models originating in the community. When this factor is taken into account, crosssector partnerships, which develop programming to expose individuals to healthy, affordable food, may have a long-term impact on the participants and the community in which they live.
\end{abstract}

(C) 2017 Californian Journal of Health Promotion. All rights reserved.

Keywords: Nutrition, Community Intervention, Minority Health, Cross-Sector Partnership

\section{Introduction}

The prevalence and significance of childhood overweight and obesity are well known issues of public health in the United States. According to the NHANES 2011-2012 data, 31.8\% of children ages 2-19 are either overweight or obese and $16.9 \%$ are obese (Ogden, Carroll, Kit \& Flegal, 2014). The consequences are farreaching. Children who are overweight or obese are more likely to stay obese as adults and develop diseases such as diabetes, asthma, depression and cardiovascular disease at a younger age (Sahoo et al., 2015). In addition, overweight and obesity in children are associated with poorer educational outcomes, which includes school absenteeism and an increased likelihood of repeating a grade. (Carey, Singh, Brown \& Wilkinson, 2015).
Family and neighborhood poverty and minority status are associated with increased BMI in children (Klebanov, Evans \& Brooks-Gunn, 2014). In the Bronx, a borough of New York City, $42.2 \%$ of children are living in poverty (New York State Community Action Association, 2016) and in New York City, 1 in 5 kindergarten students and 1 in 4 children in Head Start are obese (New York City Department of Health and Mental Hygiene, 2017).

\section{Cross-sector Partnership Programs}

Not surprisingly, there are many programs and initiatives that address obesity prevention and mitigation from a variety of angles. One important strategy uses cross-sector partnership programs to address health outcomes (Towe et al., 2016). This involves partnerships, for example, among K-12 schools, colleges, nonprofits and/or private entities, who each have 
unique assets they can bring to the partnership and a shared commitment to improving health outcomes.

This paper studies the effectiveness of a pilot partnership project between a non-profit organization called Wellness In The Schools (WITS) and Bronx Community College (BCC) and shows how a cross sector partnership may be of value for creating positive health behavior change in a community facing particular public health challenges.

WITS is a community-based organization that inspires healthy eating, environmental awareness and fitness as a way of life for kids in New York City public schools. In the Bronx, the WITS program works with schools that have a $90 \%$ or greater poverty level and are predominately attended by African American and Hispanic students. BCC is located in the South Bronx. Students who attend BCC are 65\% Hispanic and $29 \%$ African American, and many experience food insecurity.

\section{Wellness in the Schools Internship Program}

The goal of the Wellness In The Schools Internship program was to integrate BCC interns as paid interns into an already existing WITS volunteer program. Specific objectives were to provide $\mathrm{BCC}$ interns with the experience of working as promoters of health for school-aged children, ages $4-12$, in their own communities, expose students to potential career paths and provide WITS with access to college students from the community who could work in schools in the Bronx.

The particular challenge that the WITS program had faced in this community was the lack of volunteers willing to serve the schools in this area. Observing that WITS volunteer positions in Bronx schools often go unfilled, the BCC faculty project leaders felt that BCC students could fill some of these open positions and, in doing so, potentially serve as role models for New York City public school children.

Part of the reasoning was that the socioeconomic and cultural background of the interns would resemble those of the students in the participating schools. Perceived as sympathetic role models, the interns would provide an additional level of effectiveness to the program. The term relatability is used to characterize this quality of being easy to understand or to feel comfortable with because of similar experiences.

An additional objective was to identify successes and challenges for future program development and design. The project, funded by City University of New York's (CUNY) Office of Academic Affairs, was approved by the CUNY Human Research Protection Program.

BCC students taking classes in the Health Physical Education and Recreation Department were recruited in February 2016 to participate in the internship program. To be eligible, students had to demonstrate a dedication to the program, be available during NYC public school hours, and complete two trainings and required paperwork.

As part of the WITS Internship Program, BCC interns were required to work 10 hours a week for 10 weeks as paid volunteers in the WITS Cook for Kids program. The Cook for Kids program pairs chefs with volunteers to educate schoolchildren about healthy eating in the classroom and cafeteria settings. The BCC interns were paid $\$ 15$ dollars an hour and provided metro cards for travel to schools. Prior to beginning work, students were required to participate in a training regarding the Cook for Kids program conducted by WITS staff. BCC interns also participated in four food preparation-training sessions with a BCC faculty member, where they learned about food safety in the kitchen, proper cutting techniques, and became familiar with WITS recipes. Throughout the duration of the program, the interns had to report to an on-site WITS Chef and to the faculty members who were coordinating the program.

The program was evaluated using the following sources of data. BCC interns completed a presurvey with open-ended and closed-ended questions about demographic information, academic and career intentions and current number of hours working for pay each week. 
Students completed five logs, one every two weeks, which included guided questions for them to consider about their experiences working as interns in the Cook for Kids program (Table 1).

\section{Table 1}

Student Log Questions

1.Were there any significant events, successes or positive experiences?

2.Were their any challenges or disappointments you faced?

3. Did your responsibilities as a WITS' intern relate to some of the concepts you are learning about or have learned about in your classes?

4. As a college student, what impact do you think you are having on the children with whom you interact with at the school?

5. Do you have more or less of an interest in working in with underserved communities?

Table 2

Student Post Survey Question

1. What did you like most about the program and why?

2. What did you not like about the program?

3. Do you have any suggestions about how to improve the program

4. Did you encounter any time management issues because of the extra work required of the WITS internship program?

5. Describe any professional networks or relationships that resulted from your time as a WITS intern.

6. What did you learn about yourself during your experience as a WITS intern?

7. Did your time as a WITS' intern have an impact on your future career plans? Explain your answer.

8. As a WITS' intern, did you feel that you were able to develop meaningful relationships with the people you interacted with in the community? (For example the children you worked with or others you may have met from the community while working at WITS)?

The interns also completed a post survey where they answered open-ended questions about how they felt after completion of the program (Table
2). During the program, BCC faculty coordinators maintained bi-weekly journals about the successes and challenges of the program. At the end of the program, BCC faculty met with WITS staff and conducted a debriefing session where they took notes on the WITS staff overall impressions about the program.

The frequencies of responses were calculated for closed-ended questions in the student pre surveys. The faculty coordinators reviewed the interns' $\operatorname{logs}$ and post-surveys, faculty journal entries and notes from the WITS staff debriefing session. The two coordinators met to compare emergent themes and reached a consensus. The themes were then organized into larger categories of successes, challenges and lessons learned.

\section{Summary of Findings}

Ten BCC students applied to the program and seven (five female and two male) completed the internship. Four of the students were African American and three were of Hispanic descent. All intend to enroll in a four-year college upon completion of their associates' degree and pursue a career in the health field. At the start of the program, three BCC interns had no paying jobs and four were working between 10-30 hours per week.

BCC interns assisted the chef once or twice a week in preparing 40-minute classroom lessons that emphasized basic nutrition concepts and food preparation. The 7-12 school-aged children were instructed to wash their hands and were provided with plastic knives and cutting boards for vegetables or fruit. The interns' responsibilities were to circulate around the classroom and assist the schoolchildren in proper cutting techniques. The chef discussed the recipes and demonstrated how to cook the vegetables. Sample recipes included cinnamon applesauce, roasted potatoes or other easy to prepare items. The interns were also responsible for encouraging the schoolchildren to taste the prepared food. In a cafeteria activity, the interns' role was to encourage schoolchildren to try vegetables from the salad bar or a food item created by the WITS chef. 


\section{Table 3}

Themes from Interns Interactions with School Children $(n=7)$

Theme and relevant quotes

BCC students applied nutrition-related skills and health knowledge learned in classes $(n=7)$

"Many of the concepts learned in my health classes played an important role in my performance and impact on the children. It ranged from understanding impoverished neighborhoods to better eating habits that helped me have a dynamic approach to every day at the school."

"The internship gives me the opportunity to apply the concepts we have been learning in class, such as a balanced diet, portion size and my plate menu. These are being taught in the school I am working."

"One of our duties involves trying to get the kids to try new healthy foods and encourage them to ask questions about what it is, where they come from and why they are good for us. I am able to use the information I learned in my human nutrition class to answer those questions for them."

The school children were interested in learning about healthy food $(n=6)$

"This week was very interesting because there was a demonstration in the cafeteria, which involved the children trying falafels. Chef introduced a custom sauce, which many of the kids were interested in because it was made of cucumbers, their favorite vegetable."

"Another positive experience was seeing them eat for instance a carrot on their plate when they heard that carrots gives us good eye sight. It was amazing to me because it was not only the young kindergarten but also the $5^{\text {th }}$ graders who did this."

The classroom kitchen demonstrations were more effective in encouraging healthy behavior than the cafeteria activities $(\mathrm{n}=6)$

"I believe the classroom kitchen experiences were the best part of the program. The workshop, which includes the history, actual exposure to the product and interactive cooking demo was awesome as a whole. I saw the kids were really into it. These are the experiences that I believe will having a lasting impression on the kids".

"The classroom kitchen demonstration only happened twice a month but the kids loved it. Compared to the week before where we just spoke to them and had brief interactions in the cafeteria, the children were so much more responsive. It was dynamic and interacting to see all the age groups react in awe.

BCC students' presence had a positive impact on the school children $(n=6)$

"The one thing that stood out for me this week was how recognizable I was. I am only in the school a couple of times a week but this week the students really noticed me and since we have built a little bit of a friendship they were more open to greeting me and actually speaking to me."

"This past week, when I told the children I was leaving they seemed to be sad. I was surprised about the reaction of some of them because it seems I have become like family to them with all our interactions on healthy eating. Complementing them on the things they do well in the cafeteria."

"I did not have any idea how most of the children had grown fond of me until my last two weeks. Even children who have not visited the salad bar came to visit me and asked me to stay. I believe I have made a big impact on these kids, had fun as well and it was an eye opener".

BCC students enjoyed interacting with the school children $(n=5)$

"The significant part of this week was the interaction with the children... A positive experience is seeing them eat, for instance a carrot on their plate when they hear that carrot gives us good eyesight. It was amazing to me because it was not only the young kindergarten but also the $5^{\text {th }}$ graders.

"The positive experiences with the school is communicating with the kids and learning how they feel about having healthy lunches."

"Throughout all the weeks the most positive experiences were the interactions with the kids. From the salad bar, classroom kitchen demonstrations, eating with them, to playing outside with the children and showing them new basketball games that I played as a child."

Repeat exposure to healthy food changed some school children's attitudes $(\mathrm{n}=4)$

"The kids are showing a positive attitude toward the salad bar by visiting it after taking their lunch, which is good"

"The kids are now opening up to try new things, my slogan is visit the salad bar, you might like something or try something new when I invite them to visit the salad bar." 


\section{Successes}

Although the sample size was small, Table 3 highlights themes and relevant quotes regarding the positive observations noted by $\mathrm{BCC}$ students during their interactions with the schoolchildren. The interns reported applying nutrition-related skills and health knowledge in both the kitchen classroom and the cafeteria. Interns reported teaching children about basic nutrition concepts and discussing the impact of nutritious food on the body. Most schoolchildren were interested in learning about healthy food. They wanted to know about the benefits of healthy eating and were sometimes able to make the connection between diet and health.

The interns reported that the kitchen demonstrations in the classroom were more effective in encouraging healthy behavior than the cafeteria activities. During the classroom kitchen demonstrations, the interns reported that the schoolchildren were more responsive and engaged than during the brief interactions with them in the cafeteria. The schoolchildren wanted to assist in meal preparation and became excited when they saw how their favorite foods were used to create a delicious meal. Many of the interns reported feeling that their presence had a positive impact on the schoolchildren. Even though the interns were not at the school every day, the schoolchildren were excited to see them and remembered their names. The interns enjoyed interacting with the schoolchildren. Some interns noted that repeated exposure to healthy food changed some schoolchildren's attitudes toward healthy eating. Over the course of the program, some of the schoolchildren began to demonstrate positive attitudes toward healthy food while others began to show interest in trying new foods.

Table 4

Themes from the impact of the WITS program on the interns $(n=7)$

Theme and relevant quotes

Expanded professional network that resulted from being in the WITS program $(\mathrm{n}=7)$

"Being a biology major, I thought I was limited to only being able to speak about nutrition. It was interesting to find out that the chef was also studying at Cornell before he decided to become an RD. It was a connection I was not expecting and he offered me tips and advice that I will definitely use."

"I would definitely consider working in a public school as a service manager after participating in the WITS program. I think a public school is a place that a lot of people are stretched thin but need people who are passionate about health and are changing lives because of their passion."

Increased interest in working in underserved communities $(\mathrm{n}=5)$

"I have way more interest working in underserved communities because I believe in each one teach one and I would feel like I am giving back. I am not so interested in working in a school setting but I wouldn't mind teaching children in another setting a certain amount of times out of the week".

"Once I achieve my career goals, I would like to work in an underserved neighborhood... I have been where they have been and thanks to a few people who helped me, I was able to better my life."

"I think I have more interest in working with underserved communities. Our experiences influence our thinking and make us see the bigger picture. It is good to serve others, especially the underserved be it time or resources. It makes us learn and teach our family as well".

BCC students viewed themselves as role models for school children $(\mathrm{n}=5)$

"For the older kids, 4th \& 5th graders, maybe hearing that we are from the College will stick in their minds. They might think about how college students are cool because they get to help the chef. It might start planting those ideas about going to college early on."

"Regarding the school children, I believe I represent someone who looks like them that is helping to educate them about the importance of wellness. By seeing this, health and wellness no longer seems like something out of the ordinary, but something that is attainable."

"The impact I have on the children in the school is that I can relate to them more....I can ask them to tell me the truth about how they liked the foods and what they want to eat."

Interns reported changing how they prepared food for themselves and their own families $(n=3)$

"The most significant experience I had during my work experience was realizing that I could teach my son to eat healthy now instead of later...I have to expose my son to a new healthy meal 10 to 15 times in order for him to get used to the taste. I now do this with my son and it works, it just takes a lot of patience." 
Table 4 represents the relevant themes and quotes related to the impact of the WITS program on the interns. A positive aspect for the interns was the professional network or relationships that resulted from being in the WITS program. All of the interns felt the interactions with the chefs in the program resulted in an expanded view of career opportunities in the health field and options in the field of culinary arts in particular. Working in the community, and experiencing the realities of working in New York City public schools, gave some interns a sense of purpose. As a result, several interns reported they would want to work in an underserved community upon completion of an advanced degree. Some interns reported an interest in working in the public school system in the future. Other interns reported they found working in the schools too stressful and would be looking at other career options. Some BCC interns reported they viewed themselves as cultural role models for the schoolchildren having come from the same community themselves. The majority of interns felt it was important for the children to see that eating healthy, as well as going to college, can also be a part of their cultural experience. Finally, a few interns reported changing how they prepared food for their own families. They realized it was possible, through repeated exposure to healthy food, to change the eating habits of their own young children.

\section{Challenges}

BCC interns felt less positive about their role in the school cafeteria. The cafeteria atmosphere was one of chaos and loud noises. BCC interns were present to encourage schoolchildren to try new vegetables from the salad bar by providing friendly help and encouragement. However, schoolchildren had only 25 minutes to obtain and eat their food. The schoolchildren were asked by their teachers to move quickly through the food line. An intern wrote:

"One disappointing aspect is the timing and rushing. I realized the children were taking their food and not visiting the salad bar when they were in the queue." A different intern echoed a similar concern: "One of the things I felt was a little disappointing, were the lunch periods...I felt like it was so much work for little satisfaction. The last period had a bit more time and it was enough that 6 students came back to me for seconds and thirds of tomatoes, cucumbers, and peppers."

Another issue was that lack of buy-in from the kitchen staff, the teachers and the PTA volunteers. BCC interns reported feeling viewed by the staff, teachers and volunteers as hindrances. The interns reported that this particular environment was not favorable for schoolchildren to try new foods. An intern logged, "I was disappointed by the lack of collaboration of the lunchroom staff. They seemed to be upset that we were there...Part of our duties is to try to get the kids to add additional vegetables to their plate. The teachers thought we were getting in the way." Another intern wrote, "My observation is that health is a goal that is being pushed in the school, however there are many contradictions. The kitchen staff as well as WITS comes up with a great menu every month that the children do seem to love. On the other end, we have the PTA selling unhealthy snacks and beverages right outside the door of the cafeteria. Some children even see it as an option for lunch, this to me sabotages the efforts and progress the school has made. As a whole this experience has showed me how important it is to have unity in the society and have people on board."

A suggestion from the interns was that better communication with these parties about the role of the BCC interns would have reduced tensions. They also suggested that this lack of buy-in from the cafeteria staff and teachers could have been better resolved if the staff and teachers had been educated on the value of helping schoolchildren develop healthy eating habits.

\section{Lessons Learned}

In the debriefing between the WITS staff and the college professors, a few observations were noted. The WITS staff clearly appreciated the presence of the interns and felt they played an important role as change agents. The schoolchildren enjoyed having the interns present because they helped create a welcoming environment in the kitchen lab as well as in the 
cafeteria. The WITS staff also felt the BCC interns served as positive role models because of their youth, ethnicity and the lived experience they shared with the schoolchildren. At the same time, the WITS staff also wanted to remind the interns of the importance of communication regarding attendance and any work-related problems.

BCC faculty noted that even though this was a paid internship, the interns did not reduce their outside workload to accommodate the additional 10 hours a week for the program. This often resulted in more stress on the interns and some handed in their school assignments and biweekly logs late. BCC faculty had to remind the interns to submit their logs. Institutional bureaucracy from the college resulted in late start dates for some students and delays in getting them reimbursements for transportation.

\section{Conclusions}

This activity was a valuable learning experience for all the stakeholders. BCC interns were a much-appreciated resource for the WITS program. They brought a youthful energy, excellent rapport with the schoolchildren, and nutrition knowledge to the program and cultural relatability.

For some interns, the experience helped them find purpose and solidified their career goals. The income, the discipline and the purpose of the program improved their self-esteem and encouraged a feeling of empowerment.

From the perspective of the professors who supervised the project, it confirmed the effectiveness of the WITS program and the positive role of student interns. This study suggests that cross-sector partnerships, which develop programming to expose individuals to healthy, affordable food, may have a long-term impact on the participants and the community in which they live.

In terms of program design, this pilot program confirmed the effectiveness of locally recruited interns in developing rapport or cultural relatability with the schoolchildren. It may also serve as an effective model for others to use when creating partnerships to improve health outcomes.

\section{References}

Carey, F. R., Singh, G. K., Brown, H. S., 3rd, \& Wilkinson, A. V. (2015). Educational

outcomes associated with childhood obesity in the United States: cross-sectional results from the 20112012 National Survey of Children's Health. International Journal of Behavioral Nutrition and Physical Activity, 12 (Supplement 1), S3. doi: 10.1186/1479-5868-12-S1-S3

Klebanov P.K., Evans G.W., Brooks-Gunn, J. (2014) Poverty, ethnicity, and risk of obesity among low birth weight infants," Journal of Applied Developmental Psychology. 35(3), 245-253. dx.doi.org/10.1016/j.appdev.2014.01.003.

New York State Community Action Association (2016). New York State Poverty Report.

Retrieved July 13, 2017 from http://nyscommunityaction.org/PovReport/2015/FINAL\%202016\%20Poverty\%20Report.pdf New York City Department of Health and Mental Hygiene (2017). Health Topics:

Obesity. Retrieved July 13, 2017 from http://www1.nyc.gov/site/doh/health/health-topics/obesity.page Ogden, C.L., Carroll, M.D., Kit, B.K., Flegal, K.M. (2014). Prevalence of childhood and adult obesity in the United States, 2011-2012. Journal of American Medical Association. 311(8), 806814. http://doi.org/10.1001/jama.2014.732

Sahoo, K., Sahoo, B., Choudhury, A. K., Sofi, N. Y., Kumar, R., Bhadoria, A. S. (2015).

Childhood obesity: causes and consequences. Journal of Family Medicine and Primary Care, 4(2), 187192. http://doi.org/10.4103/2249-4863.154628

Towe, V. L., Leviton, L., Chandra, A., Sloan, J. C., Tait, M., \& Orleans, T. (2016).

Cross-Sector Collaborations And Partnerships: Essential Ingredients To Help Shape Health And WellBeing. Health Affairs, 35(11), 1964-1969. doi:10.1377/hlthaff.2016.0604 


\section{Author Information}

Stacia Reader, EdD, MPH

Department of Health Physical Education and Recreation, Bronx Community College

2155 University Avenue, Bronx, NY 10453

Phone: 718.289.5273

Email: stacia.reader@bcc.cuny.edu

* corresponding author 